07

\title{
Стабилизация мартенсита на нанопреципитатах и кинетика взрывообразного мартенситного перехода
}

\author{
(C) Г.А. Малыгин \\ Физико-технический институт им. А.Ф. Иоффре, \\ Санкт-Петербург, Россия \\ E-mail: malygin.ga@mail.ioffe.ru \\ Поступила в Редакцию 2 сентября 2020 г. \\ В окончательной редакции 2 сентября 2020 г. \\ Принята к публикации 2 сентября 2020 г.
}

На основе теории размытых мартенситных переходов (РМП) анализируется физический механизм влияния дисперсных наночастиц-преципитатов на возникновение таких особенностей деформационного поведения сплавов с эффектом памяти формы как стабилизация мартенсита при температурах существенно выше температур $A_{s}$ и $A_{f}$, характерных для сплава в отсутствие в нем когерентных с матрицей наночастиц. Причиной стабилизации мартенсита являются связанные с частицами поля внутренних упругих напряжений, служащие местами гетерогенного зарождения мартенсита. Теоретически продемонстрировано, что с ростом объемной концентрации наночастиц восстановление деформации памяти формы занимает все более узкий температурный интервал и происходит при все более высокой температуре. После достижения некоторого критического значения концентрации частиц возврат деформации ПФ теряет стабильность и приобретает взрывообразный характер.

Ключевые слова: сплавы с ЭПФ, дисперсные наночастицы, стабилизация мартенсита, стабильный и нестабильный (взрывообразный) мартенситный переход.

DOI: 10.21883/FTT.2021.01.50405.181

\section{1. Введение}

В настоящее время отсутствует физическая теория фазовых переходов первого рода, к которым относятся термоупругие мартенситные переходы в сплавах с эффектом памяти формы (ЭПФ). Поэтому неизвестно, какую кинетику мартенситного перехода следует считать стабильной, а какую - нестабильной. В экспериментальной практике ограничиваются описательными терминами „плавный“ или „размытый“ переход, т.е. переход, занимающий температурный интервал в несколько градусов или десятков градусов Кельвина. Или „узкий“ (sharp) мартенситный переход - переход шириной порядка нескольких градусов или долей градуса Кельвина. Предельным случаем узкого по температуре перехода является сверхузкий, взрывообразный (burstlike) мартенситный переход. В эксперименте он проявляет себя в виде скачкообразного, в течение долей секунды, восстановления деформации памяти формы (ПФ) [1-6]. Если нагреваемый кристалл свободно стоит на твердой опоре, то взрывообразный возврат деформации ПФ сопровождается подпрыгиванием кристалла над опорой [1,3-6]. Об узком мартенситном переходе можно судить также по виду калориметрических кривых, острота которых увеличивается с ростом степени предварительной деформации кристалла сплава с ЭПФ [7-10].

Исследованию кинетики взрывообразных мартенситных переходов в последнее время уделяется повышенное внимание как перспективному функциональному свойству сплавов с ЭПФ, увеличивающему быстродействие связанных с ними различных устройств, быстродействие которых обычно ограничено тепловой инерцией. Взрывообразные мартенситные переходы обнаружены в настоящее время во многих сплавах, таких, как $\mathrm{Cu}-\mathrm{Al}-\mathrm{Ni}[1-3], \mathrm{Cu}-\mathrm{Al}-\mathrm{Fe}-\mathrm{Mn}$ [6], $\mathrm{Ni}-\mathrm{Ti}-\mathrm{Nb}[8,9]$, $\mathrm{Ni}-\mathrm{Fe}-\mathrm{Ga}-\mathrm{Co}[3,4,7,10-12], \mathrm{Ni}-\mathrm{Mn}-\mathrm{Sn}-\mathrm{Tb}[13]$. B peзультате предпринятых в последнее десятилетие усилий выявлена связь взрывообразных мартенситных переходов в ряде сплавов с аномальным видом кривых их псевдоупругой деформации. А именно, с наличием на диаграммах сжатия кристаллов с ЭПФ продолжительных участков снижения деформирующих напряжений $[3-5,10,11,14,15]$. В [9] при детальном калориметрическом сканировании температурной области вблизи температуры взрывообразного мартенситного перехода обнаружено, что обратный мартенситный переход в сплаве $\mathrm{Ni}-\mathrm{Ti}-\mathrm{Nb}$ наблюдается при снижении температуры кристалла, а превращение мартенсита в аустенит происходит при постоянной температуре. При анализе результатов авторы [9] приходят к парадоксальному выводу, что обнаруженные ими эффекты находятся в противоречии с общепринятыми представлениями о термоупругой природе мартенситных превращений в сплавах с ЭПФ. В [12] при исследовании упругокалорического эффекта в кристалле сплава $\mathrm{Ni}-\mathrm{Fe}-\mathrm{Ga}-\mathrm{Co}$ найдено, что при взрывообразном характере мартенситного перехода существенно снижается адиабатический нагрев кристалла.

Относительно взрывообразного характера мартенситных переходов и недавно обнаруженных необычных связанных с ними эффектов существуют противоречи- 
вые мнения [9]. Предметом дискуссии являются два вопроса: в чем состоит причина стабильности мартенсита в деформированном сплаве при температурах, существенно превышающих температуры начала и конца перехода мартенсита в аустенит в недеформированном кристалле этого сплава, и каков кинетический механизм аномального, взрывообразного превращения деформационного мартенсита в аустенит. При обсуждении причин стабильности мартенсита часто полагают, что ими могут быть внутренние упругие напряжения в соответствующих сплавах. Их источником служат, например, когерентно связанные с матрицей наночастицы преципитатов [9,16-18]. А в пластически деформированном сплаве - поля упругих напряжений отдельных дислокаций [19] и скоплений дислокаций одного знака [20] и нанокристализованная дислокационная структура $[21,22]$. Локальные поля напряжений около дефектов являются местами гетерогенного зарождения мартенсита как при нагружении кристалла приложенным извне напряжением [19], так и при нагреве кристалла выше температур $A_{s}$ и $A_{f}$ [20]. Выполненные в последнее десятилетие исследования показали также, что возникновение взрывообразного мартенситного перехода зависит от ориентации кристаллографических осей кристалла сплава относительно направления его деформации. Так, после сжатия кристаллов сплава $\mathrm{Ni}_{49} \mathrm{Fe}_{18} \mathrm{Ga}_{27} \mathrm{Co}_{6}$ в кристаллографическом направлении [001] взрывообразное восстановление деформации ПФ не наблюдается, а после его сжатия вдоль направления [011] „взрыв“ имеет место [3,4]. Согласно $[14,15]$ сжатие кристалла вдоль направления [011] сопровождается раздвойникованием (detwinnig) мартенсита $L 1_{0}$ и поворотом габитусной плоскости, что приводит к возникновению значительных межфазных напряжений в кристалле [15].

Из приведенного выше краткого обзора видно, что узкие и сверхузкие мартенситные переходы проявляют себя в различных экспериментальных и структурных обстоятельствах. В отсутствие теории фазовых переходов первого рода и физически обоснованной теории термоупругих мартенситных переходов для каждого из этих обстоятельств приходится развивать свою теоретическую модель. Основой для нее служит обычно феноменологическая теория фазовых переходов ГинзбургаЛандау-Девоншира (ГЛД) [18]. Но в рамках этой теории трудно учесть различные структурные факторы, от которых существенно, а часто - критически, зависят указанные выше эффекты и другие особенности деформационного поведения сплавов с ЭПФ. Этих недостатков лишена теория размытых фазовых переходов (РМП) первого рода [23], являющаяся развитием теории ГЛД. Она естественным образом учитывает влияние структурных факторов на кинетику фазового перехода первого рода, в настоящей работе - мартенситного, термоупругого, сдвигового. Как будет продемонстрировано, в рамках этой теории находят объяснение парадоксальные факты, обнаруженные при калориметрическом и дилатометрическом исследовании взрывообразного мартенситного перехода в сплаве $\mathrm{Ni}-\mathrm{Ti}-\mathrm{Nb}$ [9], а также даны ответы на вопросы о причинах стабилизации мартенсита и кинетическом механизме аномального, взрывообразного превращения деформационного мартенсита в аустенит.

\section{2. Основные соотношения теории РМП}

Согласно теории РМП, относительный объем кристалла $\varphi_{M}$, занятый мартенситом, зависит от температуры $T$, внешнего напряжения $\sigma$ и межфазных напряжений $\sigma_{e}$. При одностадийном характере мартенситного перехода этот объем определяется термодинамическим соотношением $[14,23]$ :

$$
\varphi_{M}=\frac{1}{1+\exp \left(\Delta U / k_{B} T\right)},
$$

где $\Delta U=\omega \Delta u$ - изменение свободной энергии сплава при образовании в нем зародыша новой фазы объемом $\omega, \Delta u$ - объемная плотность свободной энергии фазового перехода,

$$
\Delta u=q \frac{T-T_{c 0}}{T_{c 0}}-\varepsilon_{m} \sigma-W_{e l},
$$

$q=\Delta S_{c 0} T_{c 0}-$ теплота перехода, $\Delta S_{c 0}$ и $T_{c 0}-$ изменение энтропии и характеристическая температура превращения в отсутствие внешних и внутренних напряжений, $\varepsilon_{m}$ - деформация решетки при ее структурной перестройке, $k_{B}-$ постоянная Больцмана, $W_{e l}=\sigma_{e} \varepsilon_{e l}\left(\varphi_{M}\right)-$ связанная с переходом межфазная упругая энергия,

$$
W_{e l}\left(\varphi_{M}\right)=\sigma_{e} \varepsilon_{m} \varphi_{M}\left(1-\varphi_{M}\right) .
$$

Уравнения (1a)-(1c) описывают равновесие мартенситной $\varphi_{M}$ и аустенитной $\varphi_{A}=1-\varphi_{M}$ фаз в кристалле. Наличие в соотношении (1a) структурно чувствительного элементарного объема превращения $\omega$ означает, что перемещение дислокаций фазового превращения по плоскости габитуса пространственно ограничено, например, размерами нанокристалла [24] или размером зерен в поликристалле [24], или дисперсными наночастицами [22]. Подставляя (1b) и (1c) в (1a) и разрешая это уравнение относительно напряжения $\sigma$, получаем его зависимость от температуры, межфазных напряжений и величины мартенситной деформации кристалла $\varepsilon=\varepsilon_{m} \varphi_{M}$

$\sigma=\sigma_{m}\left[\frac{T-T_{c 0}}{T_{c 0}}-a_{e} \frac{\varepsilon}{\varepsilon_{m}}\left(1-\frac{\varepsilon}{\varepsilon_{m}}\right)+\frac{1}{\bar{\omega}} \ln \left(\frac{\varepsilon / \varepsilon_{m}}{1-\varepsilon / \varepsilon_{m}}\right)\right]$,

где $a_{e}=\sigma_{e} / \sigma_{m}, \bar{\omega}=\omega q / k_{B} T_{c 0}, \sigma_{m}=q / \varepsilon_{m}=(d \sigma / d T) T_{c 0}$, $d \sigma / d T$ - коэффициент Клапейрона-Клаузиуса. Из уравнения (2) видно, что при достаточной величине структурно-чувствительного параметра $a_{e} \sim \sigma_{e}$, определяющего относительную величину межфазных напряжений, коэффициент мартенситного упрочнения кристалла $d \sigma / d \varepsilon$ может стать отрицательным [14]. Это означает, что на диаграмме сжатия кристалла появляется участок снижения деформирующего напряжения. 
Как установлено в [15], при наличии участка падения напряжения на диаграмме сжатия восстановление деформации ПФ $\varepsilon=\varepsilon_{m} \varphi_{M}$ кристалла приобретает нестабильный, взрывообразный характер. Действительно, дифференцируя соотношение (1a) по времени $t$ с учетом соотношений $(1 \mathrm{~b})$ и (1c) для межфазной упругой энергии $W_{e}$, получаем при $\sigma=0$ зависимость скорости $d h / d t$ восстановления формы (высоты) кристалла $h=h_{0}\left(1-\varepsilon_{m} \varphi_{M}\right)$ после его сжатия от объемной доли мартенсита $\varphi_{M}=\varphi[15]$ :

$$
\begin{gathered}
V(\varphi)=V_{m} \frac{4 \varphi(1-\varphi)}{1-a_{e} \bar{\omega} \varphi(1-\varphi)(1-2 \varphi)}, \\
V_{m}=h_{0} \varepsilon_{m}\left(\dot{T} / 4 T_{c 0}\right) \bar{\omega}
\end{gathered}
$$

где $V_{m}$ - максимальная скорость восстановления формы кристалла при его нагреве с постоянной скоростью $\dot{T}$ в отсутствие межфазных напряжений, т.е. при $a_{e}=0$ в знаменателе формулы (3). Очевидно, что при достаточной величине параметров $a_{e} \sim \sigma_{e}$ и $\bar{\omega} \sim \omega$ знаменатель формулы (3) может обратиться в нуль. Это означает, что кинетика восстановления формы кристалла теряет стабильность: скорость $V$ оказывается неопределенно большой, т.е. мартенситное превращение приобретает взрывной характер. Реально (физически), скорость $V$ имеет конечную величину, определяемую свободной энергией обратного мартенситного перехода [15]. Обратный переход при нагреве кристалла осуществляется в отсутствие внешнего напряжения, поэтому полагая в выражениях (1) $\sigma=0$, получаем параметрически связанную со скоростью $V(\varphi)$ температуру взрывообразного мартенситного перехода $T_{b s t}(\varphi)$,

$$
T_{b s t}(\varphi)=T_{c 0}\left[1+a_{e} \varphi(1-\varphi)-\frac{1}{\bar{\omega}} \ln \left(\frac{\varphi}{1-\varphi}\right)\right] .
$$

„Параметрически связанную“ означает, что скорость $V(\varphi)$ и температура $T_{b s t}(\varphi)$ определяются при одной и той же концентрации мартенсита $\varphi$. Отметим также, что согласно уравнению (4), чем больше величина внутренних напряжений $a_{e} \sim \sigma_{e}$, тем выше температура возврата деформации памяти формы.

\section{3. Образование мартенсита на локальных упругих напряжениях}

Эксперименты $[19,25,26]$ и расчеты согласно теории РМП $[16,20]$ показывают, что когерентные с решеткой дисперсные наночастицы $[16,25,26]$, а также отдельные дислокации и скопления дислокаций $[19,20]$ служат местами образования мартенсита в кристаллах сплавов с ЭПФ. Существующие около этих дефектов локальные поля упругих напряжений являются зонами запасенной упругой энергии. Релаксация этой энергии может происходить двумя способами: путем образования решеточных дислокаций несоответствия или путем образования дислокаций фазового (мартенситного) превращения, т. е.
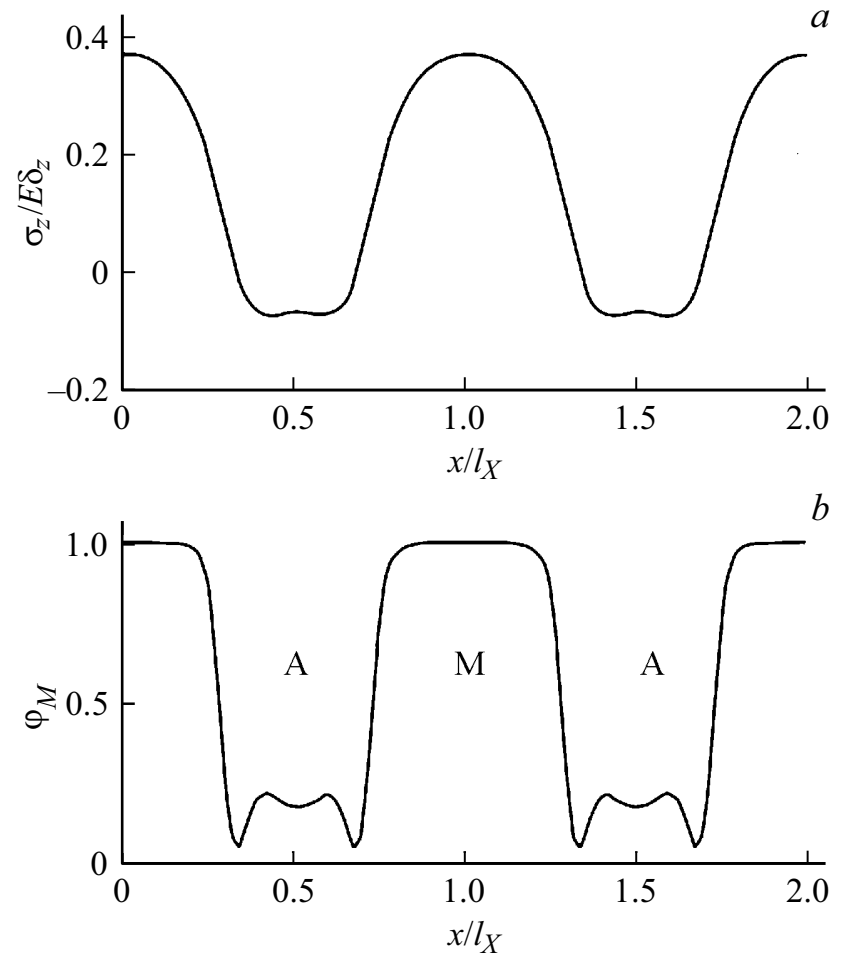

Рис. 1. Упругие напряжения $\sigma_{z} / E \delta_{z}$ в кристалле с объемной концентрацией дисперсных наночастиц $9 \%(a)$ и соответствующее распределение в нем мартенсита при температуре $T=1.05 T_{c 0}(b)[16], \delta_{z}$ - деформация несоответствия частиц и матрицы, $E$ - модуль Юнга матрицы.

путем образования мартенсита и межфазных границ мартенсит-аустенит. С межфазными границами связана межфазная энергия (1c). На рис. 1, $a$ в качестве иллюстрации показаны результаты расчета [16] локальных напряжений в „тетрагональной“ ${ }^{\circ}\left(l_{X}=l_{Y}<l_{Z}\right)$ решетке дисперсных наночастиц диаметром $2 r_{0}$ толщиной $h_{0}=0.2 r_{0}$ и расстоянием между частицами в плоскости диска $l_{X}$. Видно, что вблизи частиц величина локальных напряжений в направлении оси $z$ максимальна. На рис. $1, b$ показано соответствующее этим напряжениям распределение мартенсита $\varphi_{M}$ при температуре $T=1.05 T_{c 0}$ на расстоянии $z=2 h_{0}$ от частиц согласно соотношению (1a)

$\varphi_{M}(r, z, T)=\left[1+\exp \left(\bar{\omega}\left(\frac{T-T_{c 0}}{T_{c 0}}-\frac{\varepsilon_{z} \sigma_{z}(r, z)}{q}\right)\right)\right]^{-1}$,

где $\varepsilon_{z}(r, z)$ - компонента упругих деформаций в направлении оси $z, \bar{\omega}=60$. Символами А и М на рисунке обозначены области преимущественной концентрации, соответственно, аустенита и мартенсита. Поскольку объемная концентрация частиц при расчете составляла 9\%, то из-за сложения напряжений от соседних частиц концентрация мартенсита между ними имеет конечную величину. В [16] сделан детальный расчет напряжений и распределения R-мартенсита около частиц интерметаллида $\mathrm{Ti}_{3} \mathrm{Ni}_{4}$ в $\mathrm{B}_{2}$-структуре сплава $\mathrm{Ti}-\mathrm{Ni}$. При расчете 
предполагалось, что элементарный объем превращения значительно меньше объема наночастицы.

\section{4. Стабилизация мартенсита на дисперсных частицах}

Согласно Эшелби [27,28], средняя величина внутренних упругих деформаций в кристалле $\varepsilon_{z}$ пропорциональна концентрации $f$ в нем дисперсных частиц, $\varepsilon_{z}=\delta_{z} f$. В результате для усредненного поля внутренних напряжений имеем соотношение [16]:

$$
\sigma_{z}=\left(\frac{1-v}{1+v}\right)\left(\frac{\delta_{z} E}{1-2 v}\right) f,
$$

где $v-$ коэффициент Пуассона. Подставляя напряжение $\sigma_{z}(f) \equiv \sigma_{e}$ в $(2)$, получаем зависимость псевдоупругих напряжений от мартенситной деформации, т.е. кривую псевдоупругой деформации с учетом влияния на нее межфазных напряжений,

$$
\begin{aligned}
\sigma= & \sigma_{m}\left[\frac{T-T_{c 0}}{T_{c 0}}-a_{e}(f) \frac{\varepsilon}{\varepsilon_{m}}\left(1-\frac{\varepsilon}{\varepsilon_{m}}\right)\right. \\
& \left.+\frac{1}{\bar{\omega}(f)} \ln \left(\frac{\varepsilon / \varepsilon_{m}}{1-\varepsilon / \varepsilon_{m}}\right)\right]
\end{aligned}
$$

где

$$
\begin{gathered}
a_{e}(f)=\frac{\sigma_{z}(f)}{\sigma_{m}}=\frac{\delta_{z} \varepsilon_{m}}{1-2 v}\left(\frac{1-v}{1+v}\right)\left(\frac{E}{q}\right) f, \\
\bar{\omega}(f)=\left(\frac{1}{\bar{\omega}_{0}}+\frac{1}{\bar{\omega}_{f}(f)}\right)^{-1}=\bar{\omega}_{0}\left[1+\frac{\omega_{0}}{a_{0} d^{2}} f\right]^{-1},
\end{gathered}
$$

где $\quad \bar{\omega}_{0}=\omega_{0} q / k_{B} T_{c 0} \quad$ и $\quad \bar{\omega}_{f}=\omega_{f} q / k_{B} T_{c 0}$. Соотношение $(7 \mathrm{c})$ определяет зависимость элементарного объема фазового превращения в сплаве $\omega_{f}(f)=a_{0} l_{p}^{2}(f)$ от концентрации частиц, где $l_{p}=d / f^{1 / 2}-$ расстояние между частицами, $d-$ размер частиц, $a_{0}-$ расстояние между плоскостями габитуса, $\omega_{0}$ - элементарный объем превращения в отсутствие частиц. Температурный интервал мартенситного перехода определяется выражением $\Delta T=4 T_{c 0} / \bar{\omega}[23]$. В результате, с учетом формулы $(7 \mathrm{c})$ для зависимости размытия перехода от концентрации частиц, получаем соотношение

$$
\Delta T(f)=\Delta T_{0}\left[1+\frac{\omega_{0}}{a_{0} d^{2}} f\right],
$$

где $\Delta T_{0}=4 T_{c 0} / \overline{\omega_{0}}$ - размытие перехода в отсутствие частиц в сплаве. На рис. 2 в качестве иллюстрации приведены зависимости температурного интервала $\Delta T$ и гистерезиса $\Delta T_{h}$ мартенситного перехода в сплаве $\mathrm{Ni}-\mathrm{Mn}-\mathrm{Sn}-\mathrm{Tb}$ от концентрации преципитатов $\mathrm{Tb}$ размером $10 \mathrm{~nm}[29,30]$. Видно, что эти зависимости могут быть аппроксимированы прямыми линиями. При $T_{c 0}=290 \mathrm{~K}$ их наклоны $a_{\Delta}$ и $a_{h}$ равны, соответственно,

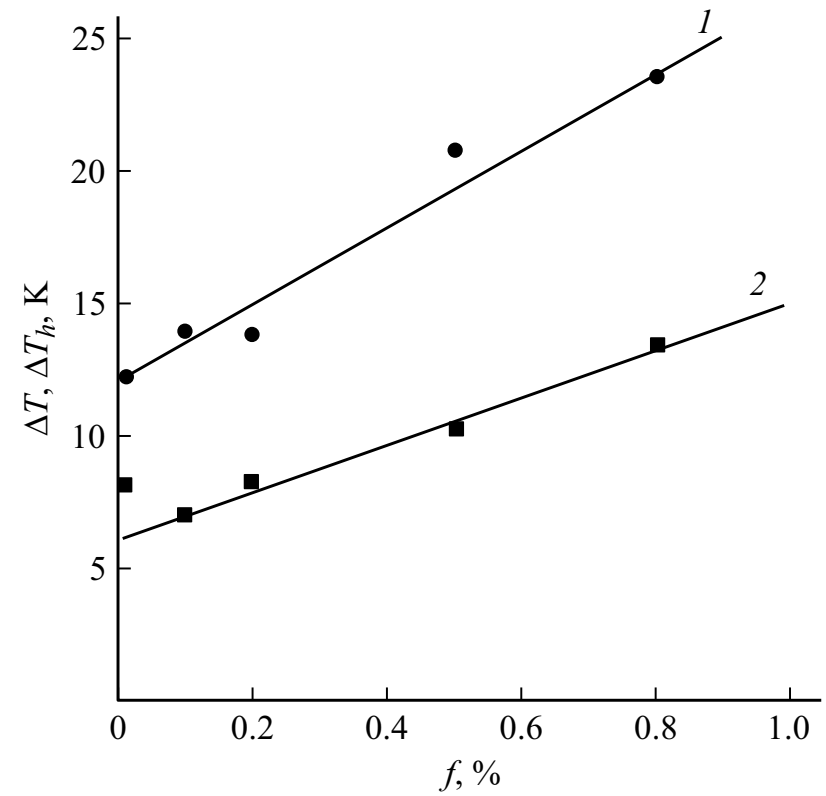

Рис. 2. Зависимости температурного интервала (1) и гистерезиса (2) мартенситного перехода в сплаве $\mathrm{Ni}-\mathrm{Mn}-\mathrm{Sn}-\mathrm{Tb}$ от концентрации преципитатов Тb размером $10 \mathrm{~nm}[29,30]$.

5.0 и 3.1. Пересечения этих прямых с осью ординат определяют величину интервала $\Delta T_{0}$ и гистерезиса $\Delta T_{h 0}$ перехода в отсутствие в сплаве наночастиц. Результаты расчета кривых псевдоупругой деформации $\sigma(\varepsilon)$ кристалла сплава с ЭПФ согласно уравнению (7a) в отсутствие и в присутствии в сплаве дисперсных наночастиц показаны на рис. 3 в единицах $\sigma_{m}, \varepsilon_{m}$. Пунктиры 1 и 2 демонстрируют эти зависимости при прямом и обратном мартенситных переходах в отсутствие частиц в сплаве, кривые 3 и 4 - соответствующие зависимости при наличии в сплаве наночастиц. Расчет произведен при следующих значениях параметров: $a_{e}=30 f, \bar{\omega}(f)=\bar{\omega}_{0}(1+5 f)^{-1}, \bar{\omega}_{0}=60$, $f=1.2 \%, \Delta T_{h 0}=0.05 T_{c 0}$. Видно, что наличие в сплаве когерентных наночастиц и связанных с ними межфазных напряжений вызывает снижение деформирующих напряжений, а разгрузка образца (кривая 4) сопровождается остаточной деформацией $\varepsilon_{r}$. То есть, появлением в кристалле остаточного мартенсита $\varphi_{r}=\varepsilon_{r} / \varepsilon_{m}$ вследствие его стабилизации на локальных напряжениях, связанных с частицами (рис. $1, b)$.

\section{5. Кинетика взрывообразного мартенситного перехода}

Согласно рис. 3 (кривая 4), деформация памяти формы, способная к возврату при нагреве кристалла сплава, равна $\varepsilon_{r}=\varepsilon_{m} \varphi_{r}$. При наличии в кристалле дисперсных наночастиц концентрация остаточного мартенсита $\varphi$ находится, согласно соотношению (1), из решения транс- 


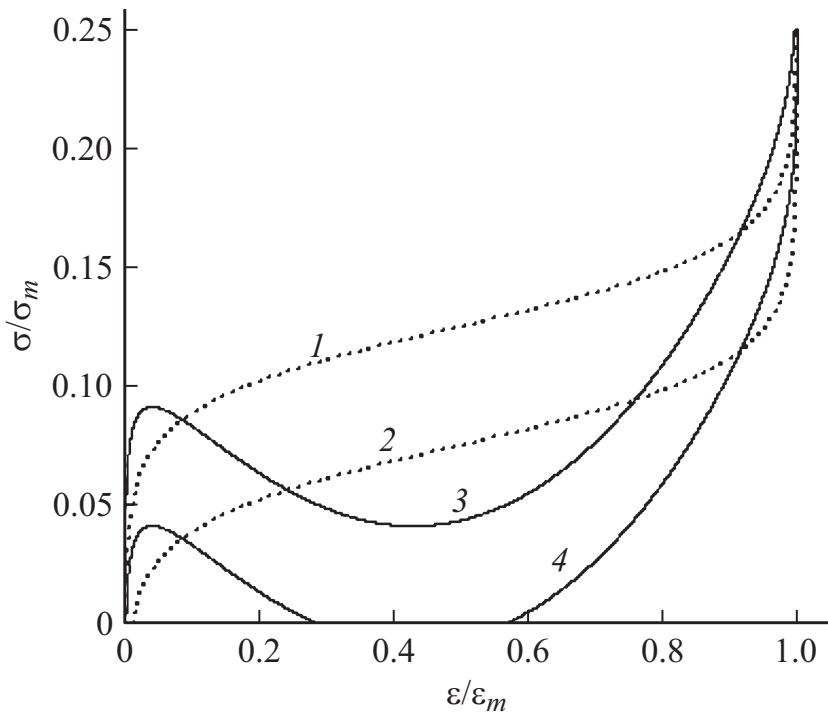

Рис. 3. Кривые псевдоупругой деформации кристалла сплава с ЭПФ в координатах $\sigma / \sigma_{m}-\varepsilon / \varepsilon_{m}$ согласно уравнению (7a) в отсутствие (пунктиры 1 и 2) и в присутствии (кривые 3 и 4 ) в сплаве дисперсных наночастиц.

цендентного уравнения

$\varphi_{r}=\left[1+\exp \left(\bar{\omega}(f)\left(\frac{T-T_{c 0}}{T_{c 0}}-a_{e}(f) \varphi_{r}\left(1-\varphi_{r}\right)\right)\right)\right]^{-1}$,

где параметры $a_{e}(f)$ и $\bar{\omega}(f)$ определяются уравнениями (7b) и (7c), соответственно. Рис. 4, а демонстрирует результаты численного расчета деформации памяти формы $\varepsilon=\varepsilon_{m} \varphi_{r}$ согласно уравнению (9) в зависимости от параметрически связанной с (9) температуры (4)

$T_{b s t}\left(\varphi_{r}, f\right)=T_{c 0}\left[1+a_{e}(f) \varphi_{r}\left(1-\varphi_{r}\right)-\frac{1}{\bar{\omega}(f)} \ln \left(\frac{\varphi_{r}}{1-\varphi_{r}}\right)\right]$

при трех значениях концентрации наночастиц: $f=0$ (пунктир), 0.34\% (кривая 1) и 1\% (кривая 2). Остальные параметры и коэффициенты те же, что при расчете кривых $\sigma(\varepsilon)$ на рис. 3. На рис. $4, b$ показана соответствующая рис. 4, $a$ скорость восстановления деформации ПФ $\dot{\varepsilon}=V / h_{0}$ при указанных выше концентрациях наночастиц. Согласно уравнению (3), эта скорость определяется соотношением

$$
\dot{\varepsilon}\left(\varphi_{r}, f\right)=\dot{\varepsilon}_{m} \frac{4 \varphi_{r}\left(1-\varphi_{r}\right)}{1-a_{e}(f) \bar{\omega}(f) \varphi_{r}\left(1-\varphi_{r}\right)\left(1-2 \varphi_{r}\right)} .
$$

Здесь $\dot{\varepsilon}_{m}=\varepsilon_{m}\left(\dot{T} / 4 T_{c 0}\right) \bar{\omega}(0)-$ максимальная скорость восстановления деформации ПФ кристалла при его нагреве с постоянной скоростью $\dot{T}$ в отсутствие межфазных напряжений $\left(a_{e}(0)=0\right)$. Для наглядности температура $T_{b s t}(10)$ на рис. 4 приведена в размерных единицах $\left(T_{c 0}=290 \mathrm{~K}\right)$.

Представленные на рис. 4, $a$ результаты расчета температурных зависимостей возврата деформации ПФ показывают, что с ростом концентрации дисперсных частиц температуры начала обратного мартенситного перехода $A_{s 1}$ и $A_{s 2}$ существенно, на $20-30 \mathrm{~K}$, смещаются в сторону более высоких температур по сравнению с температурой $A_{s}$ сплава в отсутствие в нем когерентных с матрицей преципитатов. При концентрации частиц 1\% (кривая 2) обратный мартенситный переход и возврат деформации ПФ теряют стабильный характер. Температура его начала $A_{s 2}$ существенно превышает температуру окончания $A_{f}$ перехода в отсутствие в сплаве наночастиц. Источником нестабильности деформации ПФ является возникновение на кривой 2 участка $a b$ с отрицательным наклоном $d \varepsilon / d T<0$. При температуре $312 \mathrm{~K}$, соответствующей началу отрицательного наклона кривой (обозначена буквой $a$ ) скорость возврата деформации ПФ становится неопределенно большой (рис. $4, b)$, а восстановление деформации ПФ происходит при постоянной температуре. Это обстоятельство вызвало сомнение авторов [9] относительно термоупругой природы мартенситных переходов в сплаве $\mathrm{Ni}-\mathrm{Ti}-\mathrm{Nb}$. Еще одно сделанное авторами [9] наблюдение подтвердило это сомнение. А именно, если от температуры чуть выше критической температуры 312 K (в [9] 343 K), начать снижение температуры, то мартенситный переход
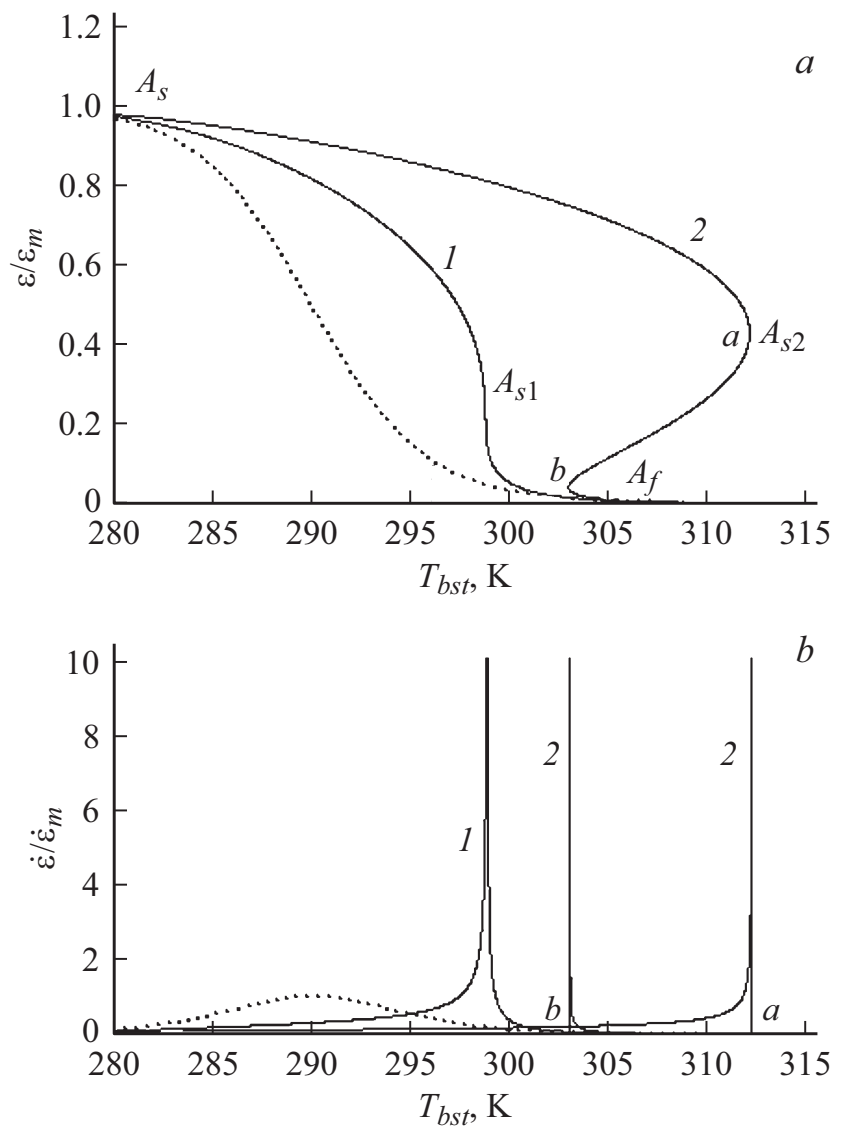

Рис. 4. Зависимости деформации (a) и скорости деформации ПФ $(b)$ от температуры $T_{b s t}(10)$ согласно уравнениям (9) и (11) в отсутствие в сплаве наночастиц (пунктиры) и при их наличии с концентрацией $0.34 \%$ (кривые 1 ) и $2 \%$ (кривые 2 ). 


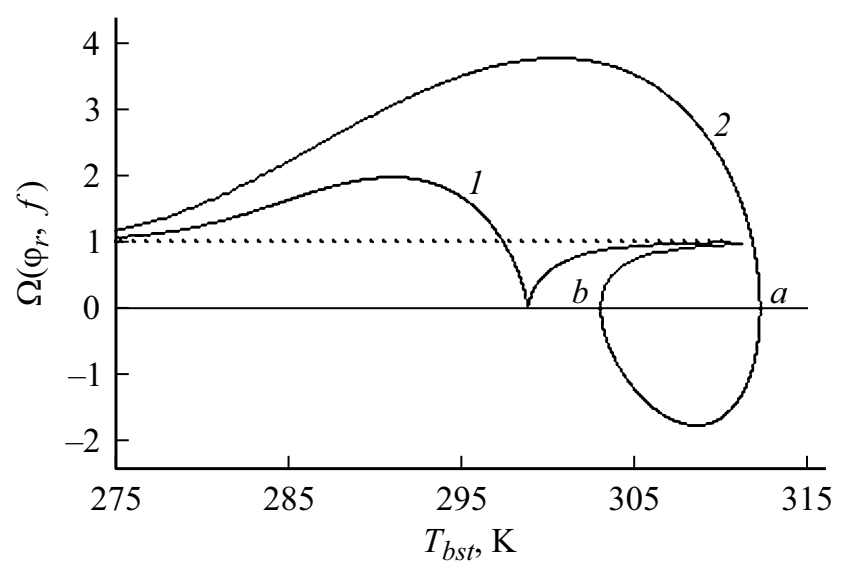

Рис. 5. Зависимость знаменателя (12) формулы (11) от температуры $T_{b s t}(10)$ в отсутствие в сплаве наночастиц (пунктир) и при их наличии с концентрацией $0.34 \%$ (кривая 1 ) и $2 \%$ (кривые 2 ).

при $312 \mathrm{~K}$ будет иметь место независимо от скорости снижения температуры. Из рис. 4, $a$ (кривая 2) видно, что такая ситуация возникает при нестабильном характере термоупругого мартенситного перехода. Приведенные на рис. 4, $b$ температурные зависимости скорости возврата деформации ПФ показывают, что в отсутствие наночастиц в сплаве фазовый переход имеет плавный характер и осуществляется в температурном интервале порядка $20 \mathrm{~K}$ (пунктир). При концентрации частиц в сплаве $0.34 \%$ этот интервал уменьшается до 1-2K (кривая 1), т.е. переход происходит в узком температурном интервале. Наконец, при концентрации частиц $1 \%$ (кривые 2) он развивается практически при постоянной температуре, т.е. становится взрывообразным и осуществляется двумя порциями $a$ и $b$ (рис. 4, $a$ ). Такая ситуация возникает при температуре $T_{b s t}(f, \varphi)$, когда знаменатель формулы (11)

$$
\Omega\left(\varphi_{r}, f\right)=1-a_{e}(f) \bar{\omega}(f) \varphi_{r}\left(1-\varphi_{r}\right)\left(1-2 \varphi_{r}\right)
$$

обращается в нуль. На рис. 5 показана параметрическая зависимость $\Omega\left(f, \varphi_{r}\right)$ от температуры $T_{b s t}\left(f, \varphi_{r}\right)$ в размерных единицах при указанных выше концентрациях наночастиц. В отсутствие частиц знаменатель $\Omega\left(\varphi_{r}, 0\right)$ равен 1 , а при концентрации частиц $0.34 \%$ обращается в нуль при $298 \mathrm{~K}$ (кривая 1). В результате скорость возврата деформации ПФ (рис. $4, b$, кривая 1 ) осуществляется в узком температурном интервале. При концентрации частиц $1 \%$ знаменатель $\Omega\left(f, \varphi_{r}\right)$ дважды обращается в нуль при температурах, обозначенных буквами $a$ и $b$ (рис. 5, кривые 2). В результате, скорость возврата деформации ПФ дважды (рис. 4, $b$, кривая 2) приобретает форму пика с нулевой по температуре шириной. Эксперименты подтверждают наличие двух пиков на кривых восстановления деформации ПФ в кристаллах сплава $\mathrm{Ni}-\mathrm{Fe}-\mathrm{Ga}-\mathrm{Co}[3]$.

\section{6. Заключение}

Таким образом, сделанный на основе теории РМП теоретический анализ обнаруженных недавно необычных фактов и особенностей деформационного поведения группы сплавов с эффектом памяти формы позволяет сделать следующие выводы.

1. Причиной необычности этих фактов и особенностей является нестабильный характер развивающихся в сплаве мартенситных процессов. Источником нестабильности служат внутренние упругие напряжения в сплаве, связанные с наличием в нем когерентных с матрицей дисперсных наночастиц-преципитатов.

2. Локальные поля упругих напряжений около преципитатов являются причиной стабилизации мартенсита при температурах существенно выше температур $A_{s}$ и $A_{f}$, характерных для сплава в отсутствие в нем наночастиц. Эти температуры тем больше, чем выше концентрация частиц в сплаве.

3. Уравнения теории РМП адекватно описывают эволюцию вида кривых восстановления деформации и скорости деформации ПФ с ростом температуры и концентрации дисперсных частиц. В отсутствие частиц процесс возврата деформации и скорости деформации ПФ занимает широкий температурный интервал, но по мере роста концентрации частиц он становится все более узким, и после достижения некоторой критической концентрации превращается во взрывообразный.

\section{Конфликт интересов}

Автор заявляет об отсутствии конфликта интересов.

\section{Список литературы}

[1] C. Picornel, J. Pons, E. Ceresary. Acta Mater. 49, 4221 (2001).

[2] V. Recarte, J.I. Pérez-Landazábal, P.P. Rodríguez, E.H. Bocanegra, M.L. Nó, J. San Juan. Acta Mater. 52, 3941 (2004).

[3] В.И. Николаев, П.Н. Якушев, Г.А. Малыгин, С.А. Пульнев. ПЖТФ 36, 83 (2010).

[4] V.I. Nikolaev, G.A. Malygin, S.A. Pulnev, P.N. Yakushev, V.M. Egorov. Mater. Sci. Forum. 738/739, 51 (2013).

[5] В.И. Николаев, П.Н.Якушев, Г.А. Малыгин, А.И. Аверкин, А.В. Чикиряка, С.А. Пульнев. ПЖТФ 40, 3, 57 (2014).

[6] Sh. Yang, T. Omori, C. Wang, Y. Liu, M. Nagasako, J. Ruan, R. Kainuma, K. Liu. Sci. Rep. 6, 21754 (2016).

[7] X. M. He, L.J. Rong, Zh. Liang, Y. Li. J. Mater. Sci. 40, 5311 (2005).

[8] M. Wang, M. Jiang, G. Liao, Sh. Guo, X. Zhao. Progr. Nature Sci. 22, 2, 130 (2012).

[9] C. Picornel, J. Pons, A. Paulsen, J. Frenzel, V. Kaminskii, K. Sapozhnikov, J. Van Humbeeck, S. Kustov. Scripta Mater. 180, 23 (2020).

[10] V.I. Nikolaev, S.I. Stepanov, P.N. Yakushev, V.M. Krymov, S.B. Kustov. Intermetallics 119, 106709 (2020).

[11] F. Xiao, M. Jin, J. Liu, X. Jin. Acta Mater. 96, 292 (2015).

[12] D. Zhao, F. Xiao, F. Nie, D. Cong, W. Sun, J. Liu. Scripta Mater. 149, 6 (2018). 
[13] P. Czaja, R. Chulist, T. Tokarsky, T. Czeppe, Y.I. Chumlyakov, E. Cesari. J. Mater. Sci. 53, 10383 (2018).

[14] Г.А. Малыгин, В.И. Николаев, А.И. Аверин, А.П. Зограф. ФTT 58, 2400 (2016).

[15] Г.А. Малыгин, В.И. Николаев, И.М. Крымов, С.А. Пульнев, С.И. Степанов. ЖТФ 89, 873 (2019).

[16] Г.А. Малыгин. ФТТ 45, 1491 (2003).

[17] Sh. Yang, Y. Liu, C. Wang, X. Liu. Acta Mater. 60, 4255 (2012).

[18] Y. Wu, J. Wang, Ch. Jiang, H. Xu. Intermetallics 97, 42 (2018).

[19] A. Ibarra, D. Caillard, J. San Juan, M.L. Nó. Appl. Phys. Lett. 90, 101907 (2007).

[20] Г.А. Малыгин. ФТТ 45, 327 (2003).

[21] J. López-García, I. Unzueta, V. Sánchez-Alarcos, V. Recarte et al. Intermetallics 94,133 (2018).

[22] Г.А. Малыгин. ФТТ 61, 1310 (2019).

[23] Г.А. Малыгин. УФН 171, 187 (2001).

[24] Г.А. Малыгин. ФТТ 61, 288 (2019).

[25] N. Nishida, T. Honma. Scripta Mater. 18, 1293 (1984).

[26] V.J. Zeldovich, G.A. Sobyanina, V.G. Pushin. Scripta Mater. 37, 79 (1997).

[27] Дж. Эшелби. Континуальная теория дислокаций. Мир, М. (1963). $247 \mathrm{c}$.

[28] D.Y. Li, L.Q. Chen. Acta Mater. 45, 471 (1997).

[29] Г.А. Малыгин. ФТТ 61, 2110 (2019).

[30] Y. Wu, J. Wang, C. Jiang, H. Xu. Intermetallics 97, 42 (2018).

Редактор Е.Ю. Флегонтова 